\title{
Power, Leadership and Culture as Drivers of Project Management
}

\author{
Biff Baker \\ Metropolitan State University of Denver
}

Leadership theory and practices existed long before Project Management became an academic discipline or theory, however little theoretical research existed regarding leadership practices as drivers of project management results. The focus of this research is on theory development within academia, that supports or refutes leadership as a catalyst or driver of the Project Management Body of Knowledge (PMBOK) functional areas. The result of this grounded-theory approach is validation and modification of leadership criteria listed in the PMBOK and a proposed meta-model for inclusion using a Be-Know-Do construct of leadership traits, knowledge and actions, and potential impact of culture upon projects.

Keywords: project management body of knowledge, leadership, motivation, culture, emotional intelligence, grounded theory, teamwork

\section{INTRODUCTION}

Leadership theory within management traces back to two authors in the last century: Mary Parker Follett and Chester Barnard. In 1926, Mary Parker Follett advocated a participatory leadership style that would unite the employer, managers, and workers to analyze situations, jointly determine solutions, and solve problems along horizontal rather than vertical lines within the organization. This idea was revolutionary because it addressed bottom-up feedback to management, in a cooperative venture to accomplish common goals that were situationally based. Her writings did not prescribe leadership principles per se, but Follett was the first writer to publish a paper on participatory-type leadership during a period in which scientific management prevailed. Many Project Management theorists and practitioners alike have adopted Follet's participatory leadership concepts (Shafritz et al., 1996, pp. 156-162).

Chester Barnard stated in The Functions of the Executive (1938) that cooperation is what holds an organization together, and it is the responsibility of an executive to ensure that this occurs. While many of the functions he espoused were transactional, some were also transformational. Barnard wrote that the executive must create vision, purpose, and mission for an organization. He or she must transmit values through formal and informal communication to ensure willingness of people to cooperate. Barnard also focused upon both material and non-material incentives as well as methods of persuasion to ensure worker's goals were aligned with the organization goals. The Functions of the Executive (1938) remains a classic work contributing to Project Management, because he described what is expected of an executive as a leader (Shafritz et al., 1996, pp. 101-111).

In addition to Follett and Barnard, Elton Mayo and F. J. Roethlisberger unquestionably contributed to the formation of the human resources and organizational behavior (HR/OB) thought 
processes. Their works enabled psychologists such as Abraham Maslow, Douglas McGregor, Frederick Herzberg, and Chris Argyris to lead the movement in human resource theory, and eventually, the Project Management Team.

Abraham H. Maslow published A Theory of Human Motivation (1943), which discussed the needs hierarchy of individuals and opened the door for managers as leaders to focus upon satisfying the five sets of goals in their workers: physiological needs, safety; love; esteem; and selfactualization which are arranged in a hierarchy of prepotency.

Douglas McGregor wrote The Human Side of Enterprise (1957), coining Theory X and Y leadership and motivational concepts, observing that Theory $\mathrm{X}$ managers believe that people do not like work and cannot be trusted and Theory Y managers believe that work can be a source of satisfaction (Shafritz 1996, 181). Frederick Herzberg proposed that there are two different classes of factors that motivate employees: hygienic factors and motivators. Hygienic factors have a range from dissatisfaction to no dissatisfaction, and the motivators coincide with higher orders of love; esteem; and self-actualization such as recognition, achievement, and growth potential. Herzberg determined that leaders desiring a highly motivated work force would ensure satisfaction of hygienic factors, but more importantly they would focus on motivators.

In 1957, Chris Argyris wrote that failure is a better teacher than success. Success results in 'single loop' learning, whereas failure results in 'double-loop' learning. Double loop learning makes people confront their failures, examine their assumptions and techniques, and correct their mistakes. Transforming or transcending leader could establish a culture that accepts honest mistakes as a vehicle for 'double-loop' learning, as exemplified by the 3M motto: "Tolerate Failure."

Drucker coined the term 'knowledge-workers' and observed that a change in economic, educational, and environmental pressures caused changes in organizational leadership and hence organizational objectives. In Managing for Results, Drucker created a practical guide for executives that organized tasks in a systemic manner. He stated that transformational leadership by executives is essential for the knowledge organization for it is the executives that must ensure that employee "knowledge and efforts contribute to economic results. [He cautions that] the knowledge worker's focus has to be on contribution rather than on the work, its skills, and its techniques" (Drucker, 1964, p. 226).

Similarly, Warren Bennis espoused the idea that leaders are made, not born. Leadership could be taught and nurtured by senior management; managers as leaders are essential to the survival of the firm. The transforming or transcending leader achieves significant change in an organization by transforming vision into reality. "It is collective, there is symbiotic relationship between leaders and followers, and what makes it collective is the subtle interplay between follower's needs and wants and the leader's capacity to understand one way or another these collective aspirations. Leadership stands in the same relationship to empowerment that management does to compliance" (Bennis, 1985, p. 218)

In summary, each of these seminal authors wrote extensively about leadership, the management of organizations and people, as well as human resource theory. Project Management as a holistic theory incorporated many parts of each of these authors into the softer category of leadership in support of project management; however, leadership was missing from the PMBOK until the most recent edition.

\section{Purpose/Aim}

This article provides an assessment and overview of the concepts of leadership and culture for Project Managers by reviewing peer-reviewed qualitative and quantitative literature to confirm or refute the Project Management Body of Knowledge (PMBOK) narrative. The aim of the paper is to provide a conceptual framework for new project managers that is validated by current studies. The results of the extensive literature review are then compared to the Project Management Institute (PMI) Talent Triangle; furthermore the paper provides comments and recommendations for changes to Chapter 3 of the PMBOK. 


\section{Be-Know-Do}

Newly appointed or inexperienced project managers occasionally have difficulty finding their niche within an organization, so this article is intended to provide a streamlined conceptualization for the leadership role of a project manager. It uses a simple concept called Be-Know-Do that was originally adapted from US Army doctrine yet remains applicable to all leaders. Very simply, the concept starts with what a leader must $B e$, what a leader must Know, and concludes with what a leader must $D o$. A new project manager can do a self-assessment by asking oneself three questions: Who am I? What do I know? and What do I need to do to ensure success? So, the next few sections will start with the doctrinal concept of power, then focus upon the leader, and finally discuss the followers within a cultural context. This paper is explorative to ascertain project related leadership issues that may need further review.

\section{What Is Power?}

Max Weber (1947) wrote that power is the ability of a person to carry out his own will despite resistance. Similarly, power is what the actor can do against the actual or possible resistance of at least one other actor (Harre ,1970; Morriss, 1987/2002; Fellows et al, 2003). Using Weber as a baseline, we begin our review with analysis of the PMBOK's sources of power. The PMBOK states that power is supported by people's perception of the leader, and identifies the following fourteen sources of power (PMI, Chapter 3, 2017):

- Positional - sometimes called formal, authoritative, legitimate (e.g. formal position granted in the organization or team)

- Reward-Oriented - ability to give praise, monetary or other desired items

- Punitive - ability to invoke discipline or other negative consequences

- Expert - skill, information possessed; experience, training, education, certification

- Referent - respect or admiration others hold for the individual

- Informational - control of gathering or distribution

- Persuasive - ability to provide arguments that move people to a desired course of action)

- Relational - participates in networking, connections, alliances

- Situational - gained due to a unique situation

- Personal or Charismatic - charm, attraction

- Integrating - apply flattery or other common ground to win favor or cooperation

- Pressure Based - limit freedom of choice or movement to gain compliance

- Avoiding - refusing to participate

- Guilt based - impose obligation or sense of duty

\section{Organizational Behavior's Personal and Positional Power}

Organizational behavior literature typically separates power into two different categories: positional and personal power. Positional power includes legitimate, coercive and reward power; whereas the personal power category includes expert, informational, referent, and persuasive power (French \& Raven, 1959; Bass, 1960; Griffin \& Phillips, 2017).

- Legitimate power is related to your position in the firm, such as being a project manager, however some PM positions may or may not include the formal ability to reward or discipline behavior (French \& Raven, 1959).

- Reward power is related to the ability to provide tangible or intangible influencers such as raises, bonuses, or recognition (French \& Raven, 1959; Weihrich \& Koontz, 1993; Newcombe, 1997).

- Coercive power includes the ability to cause compliance due to fear of punishment, such as being fired (French and Raven, 1959; Weihrich \& Koontz, 1993; Newcombe, 1997). 


\section{Personal Power}

The four types of personal power are based on the characteristics of an individual and stays with the individual regardless of where that person is located.

- Expert Power - Expert power is based on an individual's knowledge, skills, or expertise. (French \& Raven, 1959; Weihrich \& Koontz, 1993; Newcombe, 1997)

- Referent Power - Referent power is based on charisma or attractiveness to others. (French \& Raven, 1959; Weihrich \& Koontz, 1993; Newcombe, 1997)

- Informational Power - Control over information exerts power over others by providing or withholding information that others need. (Griffin \& Phillips, 2017; Hersey \& Blanchard, 1988).

- Persuasive Power - Persuasive power is based upon the persuasive use of logic and facts. (Griffin and Phillips, 2017).

\section{Relational Power}

Relational power is a similar concept to connection power, which is based upon connections with influential or important people. A leader with high connection power induces compliance from others, because they try to gain favor or avoid disfavor of the powerful connection (Hersey et.al, 1979/1988). Hence, there is some truth in the old business adage that says, "It is not what you know, but who you know." Personal power is partially related to 'what' you know; whereas relational power is related to 'who' you know. Recent research distinguishes relational power from position and personal power as it focuses on reciprocity and mutual benefits (Harvard, 2005; Zhao et. al., 2016).

\section{Other Power Sources}

The PMBOK also lists situational, charismatic, integrating, pressure-based, guilt-based, and avoiding as sources of power. However, the literature review does not substantiate these concepts as sources of power in a project environment. Situational does not refer to power, but leadership (Hersey and Blanchard, 1988); and personal or charismatic are subsets of referent power. Finally, integrating (e.g. flattery), pressure based (e.g. limit choice), guilt based (e.g. obligation) and avoiding (e.g. refusal) appear to be negotiation tactics, not per se sources of power. The literature confirms eight out of the fourteen categories listed in the PMBOK. An understanding of these power sources leads to a better understanding of the concept of individual leadership as will be discussed in the following paragraphs.

\section{LITERATURE REVIEW}

The literature review found that some leadership studies confuse the concept of leader traits, with leader knowledge and leader actions, hence the need for Be-Know-Do clarity. The author rearranged the PMBOK Leadership items into a Be-Know-Do chart by grouping these qualities and skills into three easy-to-remember conceptual categories.

\section{What a Leader Must Be}

First, one must ask, "Does the published literature support the 'Be' concept? We start by reviewing the PMBOK list of qualities and skills of a leader as shown in Figure 1 (PMI, 2017, Ch 3). Leadership begins with what the manager must be - this includes the traits that shape a leader's character. A trait is a characteristic, quality, or tendency that someone or something has. One may think of these as internal qualities, because a person possesses them all the time; whereas a trait is something that makes a person unique.

Anderson (1968) published a list of 555 words listed in descending order of likeableness; then, Bochner et al (1985) conducted a follow-on study using Anderson's techniques that resulted in a list of 110 words listed according to their social desirability. The PMBOK leadership traits that appear on his list 
include: honest, friendly, loyal, courteous, and courageous; the remaining 14 traits do not appear. This is not unusual since traits specific to a Project Manager may not appear significant to the general population.

There is an abundance of literature on leadership within corporations or generic (small business) organizations. However, this literature review investigated extant peer-reviewed literature that specifically focused upon the intersection of leadership with project management. Numerous case studies appeared but seemed to conflate the concepts of leadership, leaders, leadership traits, types of leaders, and application. Hence, the first step in this literature review was simply to isolate leader traits.

\section{FIGURE 1 \\ PMBOK QUALITIES AND SKILLS OF A BE-KNOW-DO PROJECT LEADER}

\section{BE}

- Being a visionary (e.g. describe products, goals and objectives - dream and translate dreams)

- Being optimistic and positive

- Being collaborative

- Being a problem solver and decisive.

- Being a life-long learner who is results and action oriented.

- Being ethical: honest, trustworthy, loyal \& exhibiting integrity

- Being culturally sensitive

- Being Respectful, friendly, kind, courteous, courageous

\section{KNOW}

- Knowing Technical Project Management Skills (TPMS) effectively apply project management knowledge to deliver the desired outcomes for programs or projects (also knowing where to find experts).

- Knowing Strategic and Business Management Skills (SBMS) ability to see high level overview of the organization and negotiate and implement decisions and actions that support strategic alignment and innovation (also working knowledge of finance, marketing, operations, etc.)

- Knowing the holistic and systematic view of the project, taking into account internal and external factors equally.

\section{DO}

- Applying critical thinking (e.g. application of analytical methods to reach decisions) and identify self as a change agent.

- Focusing on the important things including continuous prioritization.

- Communicating by: spending sufficient time communicating; managing expectations; accepting feedback graciously; giving feedback constructively; and asking and listening.

- Managing relationships and conflict by: building trust, satisfying concerns, seeking consensus, balancing competing and opposing goals; applying persuasion, negotiation, compromise, and conflict resolution skills; developing and nurturing personal and professional networks; taking a longterm view that relationships are just as important as the project; and continuously developing and applying political acumen.

- Building effective teams, be service oriented, and have fun and share humor effectively with team members; and give credit to others where due.

The PMBOK identifies the need to be a visionary (e.g. describe products, goals and objectives; dream and translate dreams). The literature confirms that a leader should communicate his/her vision and help the team to clarify its goals and create an exciting view to the future (Posner, 1987; Thamhain, 1991; Jiang et al, 1998; Zimmerer et al, 1998; Boehnke et al, 1999; Katzenbach et al, 2003; Lundy et al, 2003; Skipper et al, 2006; Summer et al, 2006; Grosse, 2007; Sunindijo et al, 2007; Napier et al, 2009). Baker (1997) observed that absent feelings of optimism, workers can lose heart, and can retreat from the risky realm of commitment to the safer territory of mere compliance. Being optimistic and positive are keys to inspiration; inspirational behavior is often displayed through high expectations, using symbols to focus efforts, and expressing important purposes in simple albeit symbolic ways (Posner, 1987; Boehnke et al, 1999; El Sabaa, 2001; Baker, 2002; Hayden, 2002; Humphreys 2002; Qian Shi, 2006; Sunindijo et.al. 2007).

Newmark et al (2018) identified that not only the leader, but members must have the courage to behave ethically, regardless of the difficulty of the situation because people often look for shortcuts when challenges or impediments arise. The PMBOK lists five related traits: integrity, loyalty, trustworthiness, honesty and ethics. Many researchers identified integrity as acting in a manner consistent with high ethical standards as opposed to self-interest; these traits are considered essential to a leader as well as a business (Holt, 1989; Pettersen, 1991; Thamhain, 1991; Englund, 2000; Hayden, 2002; Qian Shi, 2006; Skipper et al, 2006; Sunindijo et.al., 2007; Napier et al, 2009). 
The PMBOK identifies being courteous, friendly, kind and respectful as key leader traits. Project management leaders may not have contractional positional authority over their team, therefore informal authority is critical to success especially when the project leader is relatively junior (Clark et al, 1992). Walker et al (2000) identified that informal authority is the influence individuals have over the people with whom they interact and must be earned through respect. Respect is a two-way street that is both given and received; and collaboration is also critical to success of a project. Collaborative leadership occurs when project managers trust each other and openly decide to work together; hence, collaborative leadership is needed to ensure that individual projects align with other projects within the overall program (Thanmhain, 1991; Rowe, 2009).

A project leader must be a problem-solver, but he/she should also be a problem seeker (Hayden, 2002). The literature identifies that the best leaders are those who seek information from others for proactive problem identification (Pettersen, 1991; Jedo et al, 1999; Jiang et al, 1998; Daft, 2003; Napier et al, 2009). In addition, the leader facilitates a review of problems often with new and/or different perspectives, using intelligence and rationality while keeping disruptive emotions and impulses in check (Boehnke et al, 1999; Jiang et al, 1998; Humphreys 2002; Sunindijo et.al., 2007). Problem solving in a methodological manner is part of life-long learning; just as organizations learn over time, leaders learn new skills and tools through continuous education as well as experimenting and networking (Kaplan, 2006; Knauseder et al, 2007).

Once the root problem is isolated, and courses of action are identified, the leader must decisively or assertively insist on a course of action even though it may be unpopular and persuade others to accept his/her viewpoint (Jiang, 1998; Zimmerer, 1998; Gross, 2007). Bassellier et al (2001) concurs that being decisive is critical, but attributes specific behavior to beliefs concerning the consequences or outcomes of that behavior. Once an optimal course of action is chosen, the leader must then be action-oriented, thereby demonstrating both drive and initiative. Hence, the leader must give instructions and communicate any user-requirements to programming and support staff (Jiang, 1998; Qian Shi et al, 2006; Gross, 2007; Hoving, 2007; Sunindijo et al., 2007).

\section{Cultural Diversity and PM Cultural Awareness}

Being culturally sensitive is a leadership-mandate for projects that have great exposure to multiple cultures as we find in Multi-National Corporations (MNCs). Understanding socio-cultural similarities and differences is essential to understanding yourself as well as your team. Without adequate preparation, a leader who is executing a project overseas may experience culture shock, which is the anxiety experienced by people in a completely new environment (Oberg, 1960).

In the era of MNCs, one's project team members may not come from the same culture, which is defined as the programming of the mind that distinguishes one group or category of people from another (Hofstede, 1991). Hofstede's initial studies focused on national differences in four major categories that can have significant impact upon team members. For instance, an American manager typically is more individualistic; whereas project success in Hong Kong may require a more supportive leadership style that is compatible with a low-individualism or collectivistic society, in which harmony and paternalism are important behavioral components (Fellows et al, 2003; Kasapoglu, 2014).

Barczak et al (2006) recommended that leaders be aware of and sensitive to cultural diversity. Cultural diversity of a non-homogeneous team can have significant impact because the follower's interpretation of the project manager's leadership behaviors can vary greatly in different cultures (Kasapoglu, 2014); furthermore, behavior that yields success may vary between cultures, and success may have different meaning in different cultures (Liu et al, 2003). Uday-Riley (2006) developed a schema that incorporates culture mitigation into project management steps, for if the project manager is not aware of cultural differences, while proactively encouraging awareness, sensitivity, and patience within the team, then this may result in misunderstandings, delays in deliverables, and increased costs or at worst, project failure (Thuerbach, 2014). 
Research studies have found a high degree of cultural awareness among Hong Kong engineering firms, and that leaders often used multiple leadership styles to address different teams; there were similar case study findings in Turkey (Rawlinson et al, 1993; Walker et al, 1994; Kasapoglu, 2014). Wong et al (2007) conducted a study comparing Hong Kong Chinese and Western expatriate project managers and found that both value high productivity, emphasize project time deadlines, and efficient task performance. Their results suggested that expatriate managers seldom used indirect speech codes to avoid conflict with others, but also showed that the two groups did not significantly differ in other communication and conflict resolution dimensions; both had strong emphasis on interpersonal relationships, preferred to negotiate, avoid conflict and maintain good relationships with external parties. This is an excellent example of cultural awareness and adaptation by the expatriate project leaders (Wong et al, 2007).

\section{Emotional Intelligence}

Other leadership traits that were emphasized in the Emotional Intelligence (EI) business-oriented literature include twenty emotional competencies classified into four dimensions, namely, selfawareness, self-management, social awareness, and relationship management (Goleman, 2001). Four of these types of competencies are found within the PM literature.

- Self-awareness is to know one's own feeling as it happens and use it in decision making. It is the ability to accurately perceive own emotions and stay aware of them as they happen (Posner, 1987; Lundy et al, 2003; Qian Shi et al, 2006; Napier et al, 2009; Sunindijo \& Hadikusumo, 2014; Trejo, 2016).

- Self-control or self-management is the ability to keep emotions under control and to restrain negative actions when tempted, faced with opposition or hostility from others, or working under conditions of stress (Jedo et al, 1999; Qian Shi et al, 2006; Cheng, 2005).

- Achievement orientation refers to the manager's concern for working towards a standard of excellence. The standard may be based on the individual's own past performance, an objective measure or simply personal goals allied to project and organizational objectives (Lundy et al, 2003; Cheng, 2005; Napier et al, 2009).

- Flexibility is the ability to adapt to, and work effectively with, a variety of situations, individuals or groups. The ability to understand and appreciate different and opposing perspectives on an issue, to adapt an approach as the requirements of a situation change, and to change or easily accept changes in one's own organization or job requirements. (Posner, 1987; Pettersen, 1991; Cheng, 2005)

This concludes the portion of the literature review that asked: "What a leader must Be?" The focus in this section was upon the specific traits listed in the PMBOK that shape a leader's character and has verifiable support within the peer-reviewed literature. So, we will now transition to what a leader must know in the next section.

\section{What a Leader Must Know}

Your skills are those things you know how to do -your competence in everything from the technical side of your job to the people skills a leader requires. The PMBOK states,

- While technical project management skills are core to project management, PMI research indicates they are not enough in today's increasingly complicated and competitive global marketplace.

- Organizations are seeking added skills in leadership and business intelligence. The author modified the PMI Talent Triangle to show that 'leadership' is the bedrock of the model. Yin and Yang was added to Figure 2 to illustrate synergy among all three skills. 


\section{FIGURE 2 \\ PMBOK'S PMI TALENT TRIANGLE}

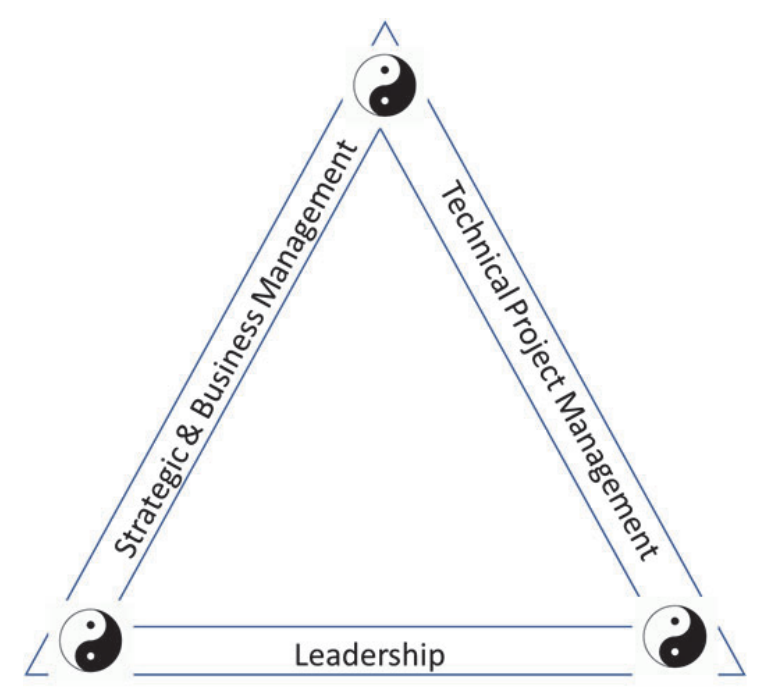

Technical Project Management Skills

Paul Gaddis (1959) was the first to publish an article addressing the roles of a project manager (PM). He identified that the PM's basic responsibilities are to "deliver his end-product (1) in accordance with performance requirements, (2) within the limitations of his budget, and (3) within the time schedule that his company or customer has specified" (Gaddis, 1959, p. 91). Hence, Gaddis emphasized cost, time, and quality, which are enduring project management legacies today.

Founded in 1969, the Project Management Institute (PMI) undertook the responsibility to capture the body of knowledge and develop a certification system for future project managers. In 1981, the PMI Board of Directors initiated a study project with three foci: ethics, standards, and accreditation. The PMI published a draft Project Management Body of Knowledge (PMBOK) in 1983 that included: scope, cost, time, quality, human resources and communications management. In 1987, a revised PMBOK added two more knowledge areas: risk management and contract/procurement management.

Technical project management skills are defined as the skills to effectively apply project management knowledge to deliver the desired outcomes for programs and projects. The Knowledge Areas in the current PMBOK,6th edition (PMI, 2017) include:

- $\quad$ Project Integration Management

- Project Scope Management

- $\quad$ Project Schedule Management

- Project Cost Management

- Project Quality Management

- Project Resource Management

- Project Communications Management

- Project Risk Management

- Project Procurement Management

- Project Stakeholder Management

Of interest to researchers, the PMBOK itself is not a double-blind, peer-reviewed document; this is in part because academic research has often lagged practitioners in this field. The development of each Knowledge Area is through a voluntary consensus, standards development process. Hence, the evolution of the PMBOK has been largely driven by practitioners asking: What works or what doesn't work? Hence, the volunteers use a variance of the grounded theory approach, as formulated 
by Glaser et al. (1967); grounding and/or 'generating' elements must be obtained through a meticulous comparative analysis of data, which is why grounded theory is also referred to as a constant comparative method (Glaser et al, 1967). It is a theoretical process that assists in bridging academic concepts with real-world experience.

The PMBOK also identifies the need for project managers to focus upon Critical Success Factors (CSF) for the project. Although substantial research has been conducted since the creation of the PMBOK, toward identifying CSF that contribute toward a universal theory of project management, no such multi-national standardized list currently exists (Baker, 2018). So, while the PMBOK recommends accessing CSF for the project, this may or may not be realistic. However, whether CSF are available or not, it is universally agreed that skills from the PMBOK are essential. Napier et al (2009) found that attribute-based competency focuses on skills-as-attributes: the extent to which the PM has acquired the necessary set of knowledge and personal characteristics. In the skills-as attributes perspective, competent PMs can be identified through their know- what, such as their mastery of project management concepts in the Project Management Body of Knowledge.

Brown (2008) determined that project leaders must be skilled in the project management processes and techniques in order to have the right thing at the right place at the right time; to integrate all the inputs into a single point of responsibility; and lead the project team members to timeous completion. That requires the application of skills and techniques as specific steps in a systematic and systemic process as per the PMBOK. A survey of 215 companies confirmed the need for technical and managerial capabilities, validating findings of numerous case studies (Posner, 1987; Thamhain, 1991; Keim, 1997; Gross, 2007; Napier et al, 2009; Polesie, 2012). In addition to knowing the PMBOK functional areas, a working knowledge of other organizational functions is also essential, which leads us to the second "know" section as follows.

\section{Strategic and Business Management Skills (SBMS)}

The PMBOK states that SBMS involve the ability to see the high-level overview of the organization and effectively negotiate and implement decisions and actions that support strategic alignment and innovation. Some of these skills may include finance, marketing, operations, or product/industry expertise. Since every project is different, the project manager should seek assistance and expertise from those who run the business in their organization (PMI, 2017). Botha (2003) found that very few project leaders start their careers in project management, but almost always in another functional skill; therefore company-trained project managers typically bring SMBS knowledge into the project.

Cheng et al (2005) found that while job-task competencies are highly specific to the industry in which one works, the behavioral competencies of superior project managers are mostly generic in nature and apply to a range of other management positions, thereby supporting the PMI Talent Triangle. Cheng's research focused upon identification of competencies that are actually-used by the 'superior' jobholders in performing effectively. Theoretically, developing these key competencies in other managers, should lead to competent high performing individuals. In addition, if the competencies are used during the selection process, then this should lead to higher success and lower costs with the fullness of time (Cheng et al, 2003/2005).

Carlton (2017) conducted research into the 'Kruger-Dunning' effect and the 'Unskilled and Unaware Problem' reaffirming that those who lack domain expertise also lack the ability to identify competence in others. So, a project manager who may be lacking in SBMS skills, may not even know it! Furthermore, he/she are unable to amend his/her own performance simply by observing the performance of others. A senior leader who lacks knowledge of information technology should not manage a complex software project; whereas, a senior leader lacking knowledge in construction has the same constraints. Qian Shi \& Jianguo Chen (2006) identified self-confidence and decisiveness as top tier leadership traits; however, disaster can occur when an executive has strong confidence, but does not have the necessary competence to ensure proper performance (Posner, 1987; Hayden, 2002; Cheng, 2005; Carlton 2017). 
In addition to TPMS and SBMS a project manager must have conceptual skills that maintain a holistic and systematic view of the project, including internal and external stakeholder priorities. Leadership is considered the prime driver for a project, and the organizational environment is a key concern and responsibility of the project manager as well as top leadership. When a systemic model is used for the project, it puts everyone on the same path; however, environmental scanning is critical to preclude speedbumps at every point along a critical path. Understanding a business situation or potential problem that will affect a project by putting the pieces together includes identifying patterns or connections between situations that are not obviously related while identifying key or underlying issues in complex situations (Odusami, 2002; Baker, 2003; Cheng, 2005; Hoving, 2007; Reich et al, 2010). Seeing the big picture distinguishes a good project manager from a great one, and a mature Project Management Office (PMO) can be of great assistance to the neophyte (Hill, 2004).

\section{What a Leader Must Do}

One cannot be an effective leader, until you apply what you know, or until you act and do what you must. Leader actions include communicating, managing conflict and relationships as well as building effective teams which will be discussed as follows. The PMBOK identifies the need to:

- Communicate: spend enough time communicating; manage expectations; accept feedback graciously; give feedback constructively; ask and listen.

- Build effective teams, be service oriented, have fun and share humor with team members; and give credit to others when due.

- Manage relationships and conflict: build trust, satisfy concerns, seek consensus, balance competing and opposing goals; apply persuasion, negotiate, compromise, use conflict resolution skills; develop and nurture personal and professional networks; take a longterm view that relationships are just as important as the project; and continuously developing and applying political acumen.

But are these PMBOK criteria supported in the project management literature? We will analyze each element separately.

\section{Communication}

When discussing communication within the context of a project, then the list of questions may include: who, what, where, when, why and how?

- Who is communicating to whom?

- Is there a feedback loop?

- What is being communicated?

- Where is the communication taking place?

- When or how often must it be communicated?

- Why is it being communicated?

- How is it being communicated?

How a message is communicated may include listening, writing, speaking as well as nonverbal communications to upper management, staff, one's teams, customers or stakeholders. Project leaders must be careful to listen to what others say and be responsive. In addition, PMs may also need to communicate or interact with other groups within their organization to promote cooperation across functional silos (Posner, 1987; Petersen, 1991; Thamhain, 1991; Jiang, 1998; Jedo et al, 1999; El Sabaa, 2001; Hayden, 2002; Odusami, 2002; Kendra et al, 2004; Napier et al, 2009; Pandya, 2014).

- Writing: Preparing written documents that accurately communicate ideas in a manner easily understood by intended readers.

- Listening: Paying attention to and concentrating on what is being said and asking questions that refine points about which one is uncertain.

- Speaking: Presenting your ideas in a manner easily understood by your audience, both in group meetings and person to person. 
- Nonverbal Communications: Reinforcing the message to others through gestures, expressions and tone/paralanguage.

\section{Nonverbal Communications}

Nonverbal communications are important because they are often culturally-based. One's culturally-based communications can have a significant impact on team development, deliverables, and increased costs simply due to misunderstandings. Hence, the project manager must be cognizant of cultural differences relative to nonverbal communications. Reinforcing one's message to others through gestures is powerful especially when combined with empathy, e.g. being able to understand how others feel or accurately determining what someone else thinks about an issue (Jiang, 1998; Thuerbach, 2014).

Effective communication consists of the verbal language used (e.g. a meaning of actual words), paralanguage (how something is said), and nonverbal body language which includes gestures and facial expressions. A significant mistake made by neophytes in the MNC or International Business environment is that they may not know that gestures may be different in different cultures. For instance, a raised thumb or a thumbs-up means 'all is good' in the western world, but in many Arabic countries thumbs-up is as profane as signaling with one's middle- finger (Morris, 1994; Axtell, 2007; Knapp et al, 2007; Matsumoto, 2006).

\section{FIGURE 3 MEHRABIAN'S ELEMENTS OF PERSONAL COMMUNICATION}

$7 \%$ spoken words $38 \%$ voice, tone $55 \%$ body language

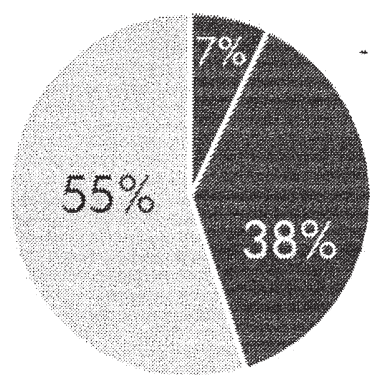

The project leader should ensure open communication, sharing relevant information throughout the organization, across functional and hierarchical levels, while remaining cognizant of different meanings related to gestures (see Figure 3). The project leader should consistently seek, while simultaneously providing information. This refers to an underlying curiosity or desire to know more about things, people or issues. Whether speaking to senior leadership, the project team or other stakeholders, the project leader should try to obtain more information and not accept situations merely at face value (Todryk, 1990; Jedo et al, 1999; Cheng, 2005; Sunindijo, 2007).

When speaking with the client, vision and inspiration are also needed but within the context of a focus upon the client's needs; focusing efforts on discovering and meeting the client's requirements, coupled with a desire to help or serve others is essential throughout all phases of the contract, especially if there are delays or other risks (lacovou et al, 2004; Cheng, 2005; Napier et al, 2009).

When speaking with the project team, the project leader should communicate his/her vision while simultaneously helping the team to clarify goals (Boehnke et al, 1999; Katzenbach \& Smith 2003; Selg, 2007; Sunindijo, 2007; Napier et al, 2009). In addition, the speech should be inspiring, which is usually displayed by the communication of high expectations, using symbology to focus efforts, and expressing important purposes in simple ways (Boehnke et al, 1999; Humphreys 2002; Summer et al, 2006; Sunindijo, 2007).

Part of team communications also includes strong listening skills. So, the project leader must grasp both facts and feelings to interpret a message's true meaning, while empathizing with others 
(Cacioppe 1997; Jedo et al, 1999; Daft 2003; Qian Shi et al, 2006; Sunindijo, 2007). As we have articulated, communicating is a critical success factor pertaining to all stakeholders, so let us now look more specifically at team building.

\section{Building Effective Teams}

There are many theories on leadership, but not all apply to project management. Hence, a search of the literature is not simply on leadership theory, but on application - e.g. what is done by successful project leaders, so that a new PM can emulate effective behavior. Projects are, by definition, not permanent; hence, project leaders must be familiar with the team building concepts of forming, storming, norming, performing and mourning as well as the concept of creative leadership intervention when blockages occur (Tuckman, 1965; Bubshait et al, 1999; Rickards et al, 2000). These concepts of team formation can be especially difficult if there is distance between the team leadership and team members inhibiting the forming and subsequent performing to a defined standard. In addition, the lack of proximity can impact upon team building as well as project quality (Hoeg et al, 2007; Windeler et al, 2018).

A project leader must be able to integrate diverse people from many different backgrounds and/or disciplines into an effective team (Odusami, 2002). The team leadership can be manifested in the form of formal authority and responsibility, but effective team leadership also requires the leader to know when not to act authoritatively if they are to get the best out of the team. The leader must demand teamwork and cooperation, which implies the genuine intention to work cooperatively with others as opposed to separately or competitively. Teamwork is normally inspired by a leader who persuades, convinces, influences and impresses others in support of the project agenda and schedule; the best leader not only achieves buy-in but can make work fun and/or rewarding (Posner, 1987; Todryk, 1990; Thamhain, 1991; Petersen, 1991; Jiang, 1998; Zimmerer et al, 1998; Jedo et al, 1999; Lambert, 2002; Cheng, 2005; Napier, 2009). Rickards et al (2000) expands this concept by saying a creative leader can be proactive at every stage of team development by emphasizing shared views (knowledge, beliefs and assumptions), a positive climate, and a commitment to ideas and alternate perspectives.

Sunindijo (2007) observed a positive correlation between leadership behaviors and emotional intelligence (El) dimensions. Project managers with high El scores used stimulating, rewarding, delegating, leading by example, open communication, listening, participating, and proactive behavior more than those leaders with lower El scores.

- Leading by example: Project leader does the same real work and contributes in the same way as subordinates (Zimmerer \& Yasin 1998; Littrell, 2002; Katzenbach \& Smith 2003; Summer et al, 2006; Sunindijo, 2007; Windeler et aI, 2018).

- Listening: Project leader grasps both facts and feelings to interpret a message's true meaning and shifts thoughts to empathizing with others (Cacioppe 1997; Jiang, 1998; Daft 2003; Sunindijo, 2007; Rojas, 2013).

- Rewarding: Project leader encourages, praises, celebrates employee accomplishments by providing rewards and positive feedback to employees who meet agreed goals. Simultaneously, the leader must provide negative feedback (and occasional punishment) to employees who show undesirable and below par performance (Daft, 2003; Jiang, 1998; Boehnke et al, 1999; Humphreys 2002; Summer et al, 2006; Sunindijo, 2007).

- Delegating: Project leader transfers authority and responsibility to lower positions in the organizational hierarchy and to enable others by providing challenging and difficult tasks to subordinates to enhance their development (Petersen, 1991; Boehnke et al, 1999; Lambert, 2002; Daft, 2003; Summer et al, 2006; Sunindijo, 2007: Napier et al, 2009).

- Participating: Project leader consults with subordinates before making decisions. Opinions, suggestions, and participation are encouraged in the decision-making process (Littrell 2002; Katzenbach \& Smith 2003; Daft, 2003; Sunindijo, 2007; Windeler et al, 2018). 
Project leaders often use directive behavior with a tone of telling people what to do; but the tone may range from asking politely, to firm, to directive, to demanding. None-the-less, the leader sets the goals, standards, rules, and the regulations for the project (Littrell, 2002; Daft, 2003; Kendra et al, 2004; Cheng, 2005; Sunindijo, 2007).

There are also appropriate times for not being too directive, but instead coaching or training, whereby the project leader pays close attention to individual differences among subordinates; and he/she teaches and advises employees with empathy, motivation and individual personal attention (Posner, 1987; Jedo et al, 1999; Humphreys 2002; Sunindijo, 2007; Koch, 2008; Napier et al, 2009).

\section{Manage Relationships \& Conflict}

Managing relationships and managing conflict are supported by a leader who is also a problemsolver. The problem-solving process is a critical characteristic of leadership that may include: problem analysis and variables, analyzing the root cause, confronting issues proactively, taking responsibility for errors, practical sense, judgement, and communicating issues and mobilizing energy of subordinates toward resolution (Petersen, 1991; Thamhain, 1991; Jedo et al, 1999; EISabaa, 2001; Hayden, 2002; Napier et al, 2009; Rojas, 2013). In addition, one's problem solving must demonstrate analytical thinking, conceptual thinking and be proactive.

\section{Analytical Thinking}

Understanding a situation by breaking it down into smaller pieces or tracing the implications of a situation in a step-by-step, causal way. It includes organizing the parts of a problem or situation in a systematic way; making systematic comparisons of different features or aspects; setting priorities on a rational basis; and identifying time sequences and causal relationship. (Thamhain, 1991; Jedo et al, 1999; Cheng, 2005; Napier, 2009)

\section{Conceptual Thinking}

Understanding a situation or problem by putting the pieces together - seeing the big picture: identifying patterns or connections between situations that are not obviously related and identifying key or underlying issues in complex situations. (Posner, 1987; Hayden, 2002; Cheng, 2005) Focusing on the important things includes continuous prioritization of tasks; whereas not seeing the big picture results in project failure due to delays, convergence of tasks, misuse of time and resources (Blackstone et al, 2009).

\section{Initiative}

The project leader must display initiative, by taking proactive actions to avert problems at an early stage, in order to enhance job results and may involve continuous prioritization. This may involve finding or creating new opportunities both inside and outside the project environment (Petersen, 1991; Jedo et al, 1999; Daft, 2003; Cheng, 2005; Qian-Shi et al, 2006; Sunindijo, 2007; Napier, 2009). Leaders who stimulate genuine inquiry help their subordinates to look at old problems from new and different perspectives, as well as apply both intelligence and rationality for problem solving (Boehnke et al, 1999; Humphreys 2002; Sunindijo, 2007).

\section{Conflict Management}

Conflict is seldom about choosing the best option in an analytical or quantitative study; it typically involves personality conflicts that may not be rational at all. Levasseur (2010) reports that project failure had 35\% technical causal factors and 65\% management causal factors - in other words, people issues. Conflict management often consumes over $20 \%$ of a project manager's time, hence leaders must recognize that the deployment of situationally appropriate responses to conflict will produce more positive individual, group, and subsequently organizational outcomes (Petersen, 1991; Thamhain, 1991; Sutterfield, 2007). 


\section{DATA ANALYSIS AND RESULTS}

The focus of this research is on theory development within academia, that supports or refutes the leadership as a key driver within the PMBOK. This study used a 'grounded theory' approach, moving from studies with empirical data and ending at the conceptual level, generating a theory or model that can be operationalized for future testing. The study used a meticulous comparative analysis between the PMBOK and the collected data, which is also referred to as a constant comparative method (Chicchi, 2000; Glaser et al, 1967). Hence, this investigation was not as methodologically straight-forward as many quantitative studies, because grounded theory approach to synthesis and analysis seeks to tease out and define underlying relationships through an inductive and intuitive interpretation of the data (Baker, 2002, p.177).

\section{THEORETICAL DEVELOPMENT MODEL}

As a result of the comparative analysis of the collected data, this study has validated the need to include leadership as a driver of the project and using grounded theory, this detailed literature review answered the following two research questions (RQ):

RQI: Is PM leadership theory sufficiently developed? Answer: Almost, but not fully.

RQ2: Have the relationships among leadership and the PM knowledge areas been empirically tested, or do they need further research? Answer: Further research in projects, with a focus on leadership as a driver is needed as well as the inter-relationships among disparate parts.

This meta-model incorporates all functional areas segmented by the phases of a project, but it also incorporates the senior leadership and project team leadership as drivers of the overall project. Communications and feedback loops were considered critical to success and are therefore indicated in this model with dashed lines among project team leadership, project team employees, senior leadership, customers, suppliers, and other external stakeholders. Many of the softer skills cannot be learned from a book, therefore communications and coordination between senior organizational leaders and the project team leadership is especially critical for success. In more complex projects, senior leaders must be visible and prepared to provide intensive, repeated assistance giving substantial time to assist teams with especially difficult problems or transformational changes (Lundy et al, 2003: Finchum, 2003; Cooper, 2007; Griffith-Cooper et al, 2007Levasseur, 2010; Fischer et al, 2018).

The PM model in Figure 4 represents a modification of Baker's (2018) meta-model for Project Quality Management. When combined with an understanding of the Be-Know-Do Leadership attributes indicated in Figure 5, the we have incorporated the current empirical data and ended at the conceptual level resulting in a much-needed PMBOK model that demonstrates leadership as a driver for all functional areas. 
FIGURE 4

META-MODEL OF LEADERSHIP \& PROJECT MANAGEMENT

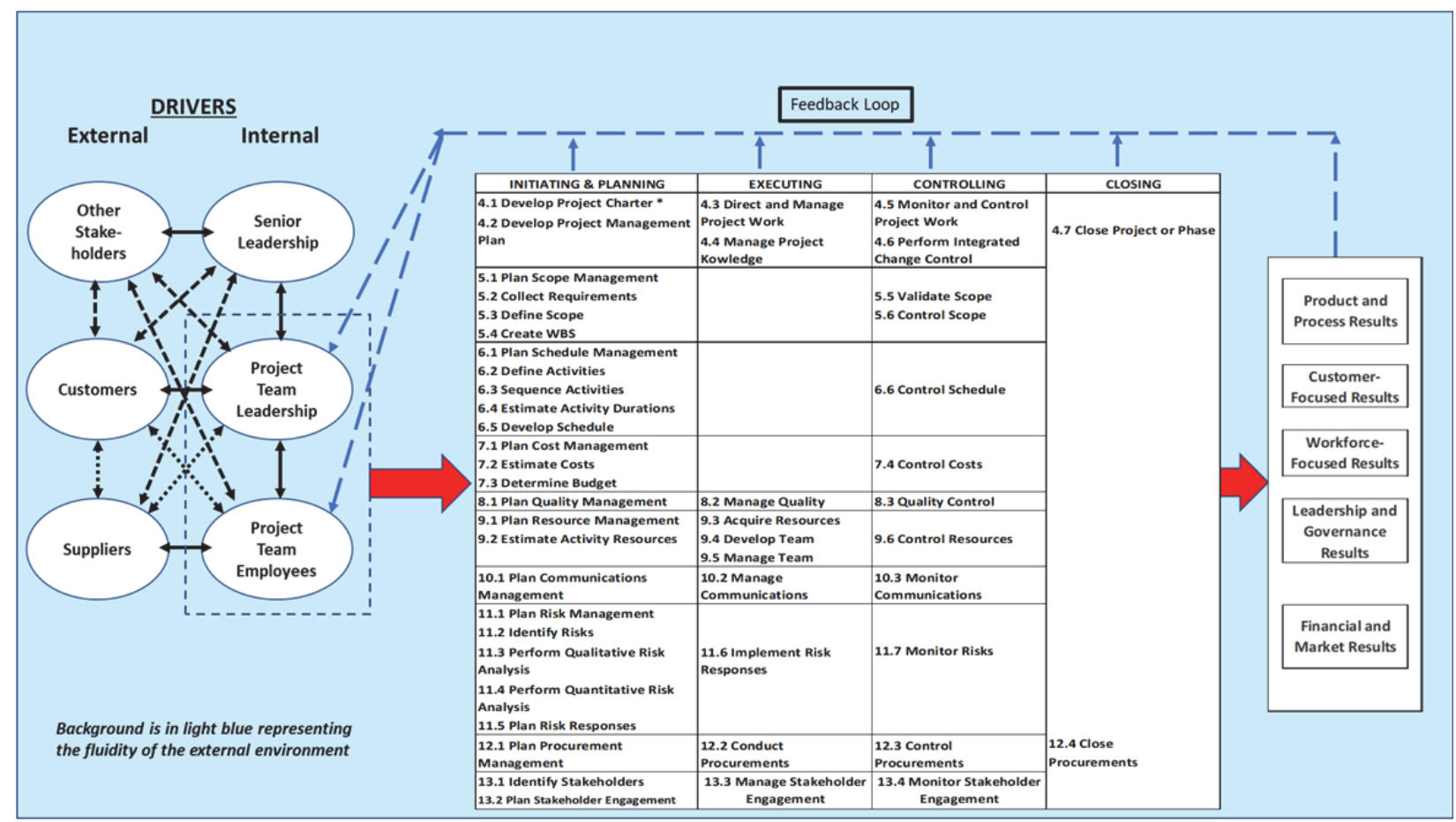

The most significant change to the Be-Know-Do criteria in Figure 1 versus the modifications found in Figure 5 was the addition of a separate requirement for negotiating and managing conflict. The PMBOK, originally had conflict management and negotiation clustered within the concept of managing relationships. Separating it thusly emphasizes the importance of negotiation found in the literature review. 


\section{FIGURE 5 \\ QUALITIES \& SKILLS FOR BE-KNOW-DO PROJECT LEADER (MODIFIED)}

\section{BE}

Being visionary e.g. describe products, goals and objectives - dream and translate dreams

Being inspirational, motivational, optimistic \& positive; likeable; levelheaded; calm; approachable Being a collaborative; team player; does not play politics

Being culturally aware: respectful, courteous, kind \& friendly

Being a life-long learner who Is results \& action oriented; courageous

Being ethical - demonstrate integrity; honesty, loyalty and trustworthiness

Being a problem-solver and decisive, even under stress.
KNOW

Knowing Technical Project

Management Skills (TPMS)

- effectively apply project

management knowledge to

deliver the desired

outcomes for programs or

projects (also knowing

where to find experts).

Knowing Strategic and

Business Management

Skills (SBMS) - ability to

see high level overview of

the organization and

negotiate and Implement

decisions and actions that

support strategic alignment

and innovation (also

working knowledge of

finance, marketing,

operations, etc.)

Knowing the environment

with a holistic \& systematic view of the project, considering

internal and external factors equally
DO

Applying critical thinking (e.g. application of analytical methods to reach decisions) and identify self as a change agent.

Focusing on the important things including continuous prioritization; remaining flexible \& removing roadblocks.

Communicating by spending sufficient time communicating; managing expectations; accepting feedback graciously; giving feedback constructively; and asking and listening. Managing relationships: building trust, satisfying concerns, seeking consensus, balancing competing and opposing goals; developing and nurturing personal and professional networks; taking $a$ long-term view that relationships are just as important as the project; and continuously developing and applying political acumen. Building effective teams: setting goals, enforcing standards, being service oriented, and having fun and sharing humor effectively with team members; show genuine concern; train and mentor; and give recognition to others where due. Negotiating \& managing conflict: negotiate as a method of conflict resolution: a problem-solving process in which parties attempt to resolve disagreement in a manner that is mutually agreeable. Styles include: insist, settle, cooperate, comply or evade.

\section{DISCUSSION AND CONCLUSIONS}

Substantial research has been conducted since the creation of the PMBOK, with kudos to practitioners who have contributed so greatly. Using grounded theory's constant comparative method, the author used joint collection, coding and analysis of data as the underlying method.

Project leadership and a project's key stakeholders come together, continuously intertwining, while simultaneously influencing PM functional areas (processes). The model begins with the customer who influences both senior leadership as well as the Project Team Leader. The senior management may have inputs from both customers as well as other external stakeholders. And the two-headed arrows represent communications among customers, suppliers, and the project leader and 
team. The dashed box indicates the boundary of the project leader and team who serve as drivers for the functional areas outlined by the PMBOK. [Please Note: The author included "identifying stakeholders" and "developing the project charter" in the Planning Phase, rather than a separate initiating phase].

The PMBOK does not adequately address "results" therefore five results were added to the metamodel: (1) Product and Process, (2) Customer-Focused, (3) Workforce-Focused, (4) Leadership and Governance and (5) Financial and Market Results. Also, a feedback loop was added in dashed lines indicating the impact of external forces upon feedback and communication. Finally, the model includes a shaded background indicating the fluid nature of the environmental impact. This model cross-correlates data from leadership and project management studies; future research should focus on the interaction of all parts of the meta-model.

This study concludes that "leadership" should be added as a driver within the PMBOK framework. Baker (2004/2018) identified that leadership is the primary driver of all project quality management processes; similarly Fortune and White identified seven Critical Success Factors (CSF) that are leadership driven. Senior leadership, the management style of senior leaders as well as the project manager; and empowerment for decision making to the lower levels were considered critical in most of the empirical studies (Baker, 2004; Baker et.al., 1986; Cooper et.al., 2007; Holland, 1999; Jaselskis, 1988; Kappelman, 2006; Might, 1985; Pinto, 1989; Somers, 2004; Sumner, 1999; Sun, 2005; The Standish Group, 1994; Tishler, 1996; Whittaker, 1999; Yeo, 2000; Yu, 2010). In conclusion, this holistic project management meta-model (Figure 4) is proposed as a framework to assist in future studies. In addition, it is recommended that the next version of the PMBOK use a Be-Know-Do construct (Figure 5) for project management leadership criteria description and development.

\section{Implications}

There are very few studies covering the leadership traits related to project management success through grounded research method; hence this study is a valuable addition to the world of literature. The study would also assist corporate/organizations to identify the key competencies of a project leader so that the organization focuses on identified competencies for any new appointment/assignment of a project leader or development of their existing project staff using a Be- Know-Do construct.

\section{Limitations}

The study focused on identifying key traits (Be), knowledge (Know) and Actions (Do) of a project leader, starting with the PMBOK and validating each subcategory with peer-reviewed literature. We must explore each sub-component of the groupings and identified themes in greater detail. Also, there is a need to explore their individual impact on the project results and the performance rate in different cultures since the Be-Know-Do components may vary from one culture to another.

\section{Future Scope}

Researchers can adopt focus groups or in-depth interviews, followed by structured questionnaires to capture the specific dimension of each sub-component of the Be-Know-Do construct in greater detail. Further, the researcher can adopt mix research methodology (quantitative and qualitative) to explore each component and their individual impact on the project success with higher validity and reliability and may arrive at new observations and findings. Future meta-analysis research across multiple countries, using the same research questions would assist in identifying leadership variances by culture. 


\section{REFERENCES}

Anderson, N. H. (1968). Likableness ratings of 555 personality-trait words. Journal of Social Psychology, 9, 272-279.

Andres, H. P., \& Zmud, R. W. (2001). A Contingency Approach to Software Project Coordination. Journal of Management Information Systems, 18(3), 41-70.

Axtell, R. E. (2007). Essential Do's and Taboos: The Complete Guide to International Business and Leisure Travel. Hoboken, New Jersey: John Wiley \& Sons, Inc.

Baker, B. (1997). Communication, commitment, and the management of meaning. PM Network, 11(12), 35-37.

Baker, B. (2002). Leadership and the project manager. PM Network, 16(12), 20.

Baker, B. (2004). TQM Practice and Theory: A Meta-Analysis of Empirical Studies. Dissertation Abstracts International, 65(1A), 206. Publisher is ProQuest Information \& Learning (formerly UMI), Ann Arbor Michigan 48106. Publication \#3117237.

Baker, B. (2018). Project Quality Management Praxis and Theory. American Journal of Management, 18(3), 1-11.

Baker, M. J. (2002). Research methods. The Marketing Review, 3(1), 167-193.

Barczak, G., McDonough, E. F., \& Athanassiou, N. (2006). So You Want to Be a Global Project Leader? Research Technology Management, 49(3), 28-35.

Bass, B. M. (1960). Leadership, psychology, and organizational behavior. New York: Harper.

Bassellier, G., Reich, B. H., \& Benbasat, I. (2001). Information Technology Competence of Business Managers: A Definition and Research Model. Journal of Management Information Systems, 17(4), 159-182.

Bech, N. (2001). Open Doors to Leading Projects: Your New Chance to Understand and Perform Project Leadership. Creativity \& Innovation Management, 10(2), 96.

Blackstone, J. H., Cox, J. F., \& Schleier, J. G. (2009). A tutorial on project management from a theory of constraints perspective. International Journal of Production Research, 47(24), 7029-7046.

Botha, M. C. (2003). Formulating and implementing a strategy for project management in the Eden District Municipality. Unpublished dissertation for the MBA degree, University Stellenbosch Business School, Bellville.

Bochner, S., \& van Zyl, T. (1985). Desirability Ratings of 110 Personality-Trait Words. Journal of Social Psychology, 125(4), 459.

Boehnke, K., Distefano, A. C., DiStefano, J. J., \& Bontis, N. (1999). Leadership for extraordinary performance. IEEE Eng. Manage. Rev., 32-37.

Brown, C. J. (2008). A comprehensive organizational model for the effective management of project management. South African Journal of Business Management, 39(3), 1-10.

Bubshait, A. A., \& Farooq, G. (1999). Team Building and Project Success. Cost Engineering, 41(7), 34.

Carlton, D. (2017). Competence versus confidence in IT Project Leadership and its Impact on Project Outcomes. Journal of Modern Project Management, 38-45.

Cheng, M., Dainty, A., \& Moore, D. (2003). The differing faces of managerial competency in Britain and America'. Journal of Management Development, 22(6), 527-537.

Cheng, M., Dainty, A., \& Moore, D. (2005). What makes a good project manager? Human Resource Management Journal, 15(1), 25-37.

Chicchi, F. (2000). Grounded theory and the biographical approach: An integrated heuristic strategy. International Review of Sociology, 10(1), 1-19.

Clark, K. B., \& Wheelwright, S. C. (1992). Organizing and Leading "Heavyweight" Development Teams. California Management Review, 34(3), 9-28.

Cooper, R. G. (2007). Grappling with Innovation. Research Technology Management, 50(5), 7-8.

Daft, R. L. (2003). Management, 6th Ed. Thomson South-Western.

Drucker, P. F. (1973). Management: Tasks, Responsibilities, Practices. New York: Harper and Row. 
El-Sabaa, S. (2001). The skills and career path of an effective project manager. International Journal of Project Management, 19(1), 1-7.

Englund, R. L. (2000). Authenticity and integrity. PM Network, 14(8), 73-75.

Fellows, R., Liu, A., \& Fong, C. M. (2003). Leadership style and power relations in quantity surveying in Hong Kong. Construction Management \& Economics, 21(8), 809-818.

Finchum, M. J. (2003). Cultivating the Next Crop of Leaders. Leadership \& Management in Engineering, 3(3), 150.

Fisher, C. M., Pillemer, J., \& Amabile, T. M. (2018). Deep Help in Complex Project Work: Guiding and Path-Clearing Across Difficult Terrain. Academy of Management Journal, 61(4), 15241553.

French, J. R. P., \& Raven, B. (1959). The bases of social power. In Cartwright, D. (ed.), Studies in Social Power. University of Michigan, Ann Arbor, MI.

Gaddis, P. O. (1959, May). The Project Manager. Harvard Business Review.

Glaser, B. G., \& Strauss, A. L. (1967). The Discovery of Grounded Theory: Strategies for qualitative research. Chicago: Aldine.

Goleman, D. (2001). An El-based theory of performance. The emotionally intelligent workplace, C. Cherniss and D. Goleman, Eds., JosseyBass, 27-44.

Goleman, D., \& Nevarez, M. (2018). Emotional Intelligence: Boost Your Emotional Intelligence with These 3 Questions. Harvard Business Review Digital Articles, 2-5.

Griffith-Cooper, B., \& King, K. (2007). The Partnership between Project Management and Organizational Change: Integrating Change Management with Change Leadership. Performance Improvement, 46(1), 14-20.

Grosse, D. (2007). Leadership in R\&D Projects. Creativity \& Innovation Management, 16(4), 447-456.

Harre, R. (1970). Powers. British Journal of the Philosophy of Science, 21, 81-101.

Harvard Business Essentials. (2005). Power, influence and persuasion (pp. 15e32). Boston, MA: Harvard Business School Publishing Press.

Hayden, W. M. (2002). Navigating the White Water of Project Management. Leadership \& Management in Engineering, 2(2), 20.

Hersey, P., \& Blanchard, K. H. (1988) Management of Organizational Behavior: Utilizing Human Resources, 5th edition. Prentice-Hall, Englewood Cliffs, NJ.

Hersey, P., Blachard, K. H., \& Natemeyer, W. E. (1979). Situational Leadership, Perception, and the Impact of Power. Group \& Organization Studies, 4(4), 418-428

Hill, G. M. (2004). Evolving the Project Management Office: A Competency Continuum. Information Systems Management, 21(4), 45-51.

Hoegl, M., Ernst, H., \& Proserpio, L. (2007). How Teamwork Matters More as Team Member Dispersion Increases. Journal of Product Innovation Management, 24(2), 156-165.

Holt, L. (1989). Project management excellence: The Shell Stanney case. Construction Management \& Economics, 7(3), 217.

Hoving, R. (2007). Information Technology Leadership Challenges - Past, Present, and Future. Information Systems Management, 24(2), 147-153.

Humphreys, J. H. (2002). Transformational leader behavior, proximity and successful services marketing. J. Services Marketing, 16(6), 487-502.

lacovou, C. L., \& Dexter, A. S. (2004). Turning Around Runaway Information Technology Projects. California Management Review, 46(4), 68-88.

Jedo, J., \& Clements, J. P. (1999) Successful Project Management. Southwestern College Publishing.

Jiang, J. J., Klein, G., \& Margulis, S. (1998). Important behavioral skills for IS project managers: The judgments of experienced IS professionals. Project Management Journal, 29(1), 39.

Kaplan, R. M. (2006). Higher education. PM Network, 2(2), 30-31.

Kasapoglu, E. (2014) Leadership Styles in Architectural Design Offices in Turkey. Journal of Construction Engineering \& Management, 140(2), 1.

Katzenbach, J. R., \& Smith, D. K. (2003). The Wisdom of Teams. Harper-Business Essentials. 
Kendra, K. A., \& Taplin, L. J. (2004). Change Agent Competencies for Information Technology Project Managers. Consulting Psychology Journal: Practice \& Research, 56(1), 20-34.

Knapp, M. L., \& Hall, J. A. (2007). Nonverbal Communication in Human Interaction. Boston, MA: Wadsworth and Cengage Learning, Inc.

Knauseder, I., Josephson, P-E., \& Styhre, A. (2007). Learning approaches for housing, service and infrastructure project organizations. Construction Management \& Economics, 25(8), 857-867.

Koch, D. C. (2008). Increasing Field Use of Planning, Scheduling and Project Cost through Assessed Training Programs. AACE International Transactions, 1-4.

Lambert, L. R. (2002). Leadership-The Invisible Cost Category. AACE International Transactions, 10, 1.

Littrell, R. F. (2002). Desirable leadership behaviors of multicultural managers in China. Journal of Management Development, 21(1), 5-74.

Levasseur, R. E. (2010). People Skills: Ensuring Project Success--A Change Management Perspective. Interfaces, 40(2), 159-162.

Liu, A. M. M., \& Fang, Z. (2006). A power-based leadership approach to project management. Construction Management \& Economics, 24(5), 497-507.

Liu, A., Fellows, R., \& Fang, Z. (2003). The power paradigm of project leadership. Construction Management \& Economics, 21(8), 819-829.

Lundy, V., \& Morin, P. P. (2013). Project Leadership Influences Resistance to Change: The Case of the Canadian Public Service. Project Management Journal, 44(4), 45-64.

Matsumoto, D. (2006). Culture and Nonverbal Behavior. In V. Manusov \& M. Patterson (Eds.), The Sage Handbook of Nonverbal Communication (pp. 219-235). Thousand Oaks: Sage.

Mehrabian, A. (1971). Silent Messages (1st ed.). Belmont, CA: Wadsworth. ISBN 0-534-00910-7.

Morris, D. (1994) Bodytalk: The Meaning of Human Gestures. New York: Random-House, Inc.

Miller, C., \& Subbiah, K. (2012). A Five-Factor Model for Success of Internal Consultants. SAM Advanced Management Journal, 77(1), 4-12.

Morriss, P. (1987/2002). Power: a philosophical analysis. Manchester: Manchester University Press.

Napier, N. P., Keil, M., \& Tan, F. B. (2009). IT project managers' construction of successful project management practice: a repertory grid investigation. Information Systems Journal, 19(3), 255282.

Newcombe, R. (1997). Procurement paths -- a cultural/political perspective. In Davidson, C.H. and Megind, T.A. (Eds.), Procurement -- a key to innovation, Proceedings of CIB W92, IF Research Corporation, Montreal.

Newmark, R. I., Dickey, G., \& Wilcox, W. E. (2018). Agility in Audit: Could Scrum Improve the Audit Process? Current Issues in Auditing, 12(1), A18-A28.

Oberg, K. (1960). Cultural shock: adjustment to new cultural environments. Practical Anthropology, 7 , $177-182$.

Odusami, K. T. (2002). Perceptions of Construction Professionals Concerning Important Skills of Effective Project Leaders. Journal of Management in Engineering, 18(2), 61.

Pandya, K. D. (2014). The Key Competencies of Project Leader Beyond the Essential Technical Capabilities. IUP Journal of Knowledge Management, 12(4), 39-48.

Pettersen, N. (1991). Selecting project managers: an integrated list of predictors. Project Management Journal, 22(2), 21-26.

Polesie, P. M. A. (2012). Reducing the use of resources in medium-sized Swedish construction enterprises: production managers' views. Construction Management \& Economics, 30(3), 193 202.

Posner, B. Z. (1987). What it takes to be a good project manager. Project Management Journal, 18(1), 51-54.

PMI - Project Management Institute. (2017). A guide to the project management body of knowledge (PMBOK® Guide), 6th ed. Newtown Square, Pa.: Project Management Institute, Inc.

Qian, S., \& Chen, P. J. (2006). Human Side of Project Management: Leadership Skills. Project Manager Institute. Newtown Square, PA. 
Reich, B. H., \& Sauer, C. (2010). Roles of the External IT Project Manager. Communications of the $A C M, 53(5), 126-129$.

Rens, K. L., \& Rens, A. J. (2010). Leading, Learning, and Living the Shackleton Way: Education and Practice. Leadership \& Management in Engineering, 10(1), 32-40.

Rickards, T., \& Moger, S. (2000). Creative Leadership Processes in Project Team Development: An Alternative to Tuckman's Stage Model. British Journal of Management, 11(4), 273.

Rojas, E. M. (2013). Identifying, Recruiting, and Retaining Quality Field Supervisors and Project Managers in the Electrical Construction Industry. Journal of Management in Engineering, 29(4), 424-434.

Rowe, S. F. (2009). Collaborative project leadership: program management from the project manager's perspective. Paper presented at PMI ${ }^{\circledR}$ Global Congress 2009-North America, Orlando, FL. Newtown Square, PA: Project Management Institute.

Rawlinson, S., Ho, T. K. K., \& Po-Hung, Y. (1993). Leadership style of construction managers in Hong Kong. Construction Management \& Economics, 11(6), 455.

Selg, R. A., \& Rihel, D. R. (2007). Successfully Managing One-Of-A-Kind Projects. AACE International Transactions, 05.1-5.4.

Shafritz, J. M., \& Ott, S. (1996). Classics of organization theory, (4th ed.) NY: Harcourt Brace.

Skipper, C. O., \& Bell, L. C. (2006). Assessment with $360^{\circ}$ Evaluations of Leadership Behavior in Construction Project Managers. Journal of Management in Engineering, 22(2), 75-80.

Summer, M., Bock, D., \& Giamartino, G. (2006). Exploring the Linkage between the Characteristics of It Project Leaders and Project Success. Information Systems Management, 23(4), 43-49.

Sunindijo, R. Y., Hadikusumo, B. H. W., \& Ogunlana, S. (2007). Emotional Intelligence and Leadership Styles in Construction Project Management. Journal of Management in Engineering, 23(4), 166-170.

Sunindijo, R. Y., \& Hadikusumo, B. H. W. (2014). Emotional Intelligence for Managing Conflicts in the Sociocultural Norms of Thai Construction Industry. Journal of Management in Engineering, 30(6), 1.

Sutterfield, J. S., Friday-Stroud, S. S., \& Shivers-Blackwell, S. L. (2007). How NOT to Manage a Project: Conflict Management Lessons Learned from a DOD Case Study. Journal of Behavioral \& Applied Management, 8(3), 218-238.

Tansley, C., \& Newell, S. (2007). Project social capital, leadership and trust: A study of human resource information systems development. Journal of Managerial Psychology, 22(4), 350-368.

Tappan, D. S., Jr. (1985). Project Management of the Future. Columbia Journal of World Business, 20(4), 27.

Thamhain, H. J. (1991). Developing project management skills. Project Management Journal, 22(3), 39$44,53$.

Thomas, D. M., \& Bostrom, R. P. (2010). Vital Signs for Virtual Teams: An Empirically Developed Trigger Model for Technology Adaptation Interventions. MIS Quarterly, 34(1), 115-142.

Thuerbach, C. (2014). This IS your grandfather's project management: Building a trust-based team. Paper presented at PMI ${ }^{\circledR}$ Global Congress 2014-North America, Phoenix, AZ. Newtown Square, PA: Project Management Institute.

Todryk, L. (1990). The project manager as team builder: creating an effective team. Project Management Journal, 21(4), 17-22.

Trejo, A. (2016). Project Outcomes Improved by Emotional Intelligence. Business Perspectives \& Research, 4(1), 67-76.

Tuckman, B. (1965). Development sequence in small groups, Psychological Bulleting, 63(6), 384-399.

Uday-Riley, M. (2006). Eight critical steps to improve workplace performance with cross-cultural teams. Performance Improvement, 45(6), 28-32.

Walker, A., \& Kalinowski, M. (1994). An anatomy of a Hong Kong project--organization, environment and leadership. Construction Management \& Economics, 12(3), 191. 
Walker, A., \& Newcombe, R. (2000). The positive use of power on a major construction project. Construction Management \& Economics, 18(1), 37-44.

Wanberg, J., Harper, C., Hallowell, M. R., \& Rajendran, S. (2013). Relationship between Construction Safety and Quality Performance. Journal of Construction Engineering \& Management, 139(10), 1.

Windeler, J. B., Maruping, L., \& Venkatesh, V. (2018). Technical Systems Development Risk Factors: The Role of Empowering Leadership in Lowering Developers' Stress. Information Systems Research, 29(4), 775-796.

Weber, M. (1947). The Theory of Social and Economic Organisation. In Henderson, A.H. and Parsons, T. (eds), first published in 1924. Free Press, Glencoe, IL.

Weihrich, H., \& Koontz, H. (1993). Management: A Global Perspective. McGraw-Hill, New York.

Wong, J., Wong, P. N. K., \& Li, H. (2007). An investigation of leadership styles and relationship cultures of Chinese and expatriate managers in multinational construction companies in Hong Kong. Construction Management \& Economics, 25(1), 95-106.

Zhao, X., Shang, Y., Lin, J., Tan, J., Li, H., \& Liu, T. (2016). Leader's relational power: Concept, measurement and validation. European Management Journal, 34(5), 517-529.

Zimmerer, T. W., \& Yasin, M. M. (1998). A leadership profile of American project managers. IEEE Engineering Management Review, 5-11. 